\title{
Experimental Investigations and Computational Analysis on Subsonic Wind Tunnel
}

\author{
Rishabh Kumar Sahu, Saurabh Sharma, Vivek Swaroop, Vishal Kumar \\ B.Tech Student, Department of Mechanical Engineering, \\ ABES Engineering College, Ghaziabad, Uttar Pradesh, India
}

\begin{abstract}
How to cite this paper: Rishabh Kumar Sahu | Saurabh Sharma | Vivek Swaroop | Vishal Kumar "Experimental Investigations and Computational Analysis on Subsonic Wind Tunnel" Published in International Journal of Trend in Scientific Research and Development

(ijtsrd), ISSN: 2456-

6470, Volume-3 |

Issue-3, April 2019,

pp.1708-1711, URL:

https://www.ijtsrd.c

om/papers/ijtsrd23

511.pdf

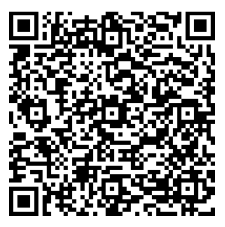

IITSRD23511

Copyright (C) 2019 by author(s) and International Journal of Trend in Scientific Research and Development Journal. This is an Open Access article distributed under the terms of the Creative Commons

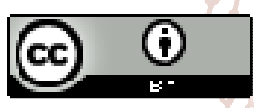
Attribution License (CC BY 4.0) (http://creativecommons.org/licenses/ by $/ 4.0$
\end{abstract}

\section{INTRODUCTION}

The wind tunnel is an instrument to think about fluid flow around a body and the forces generated by the fluidstructure interaction. A wind tunnel experiment gives the pressure and forces values on the model and the stream perception. In perspective on the course through the entry circuit, the wind tunnel is of two types, open type and closed type. In open type, surrounding air enters from one side and exits to the environment ensuing to coursing through the section. The fundamental objective of wind tunnel configuration is to include uniform stream inside the test chamber. Test chamber measurement relies upon the kind of test to be performed and the degree of the model to be attempted. The wind tunnel's general measurements are key factors in its advancement and running costs. The trade-off is required between the restricting requirements to get a reasonable structure of the wind tunnel, fulfilling the test prerequisites, space and budget constraints. Basic parts of an open type wind tunnel are the test area, contraction cone, diffuser, settling chamber and driving unit (Axial fan).

\section{COMPONENTS OF WIND TUNNEL}

\subsection{INLET/SETTLING CHAMBER}

The purpose of a settling chamber containing honeycombs and screens is to reduce the stream turbulence before it enters the cone. An assurance of honeycomb and screens for a wind tunnel is especially dependent on the test type to which the passage is arranged. The honeycomb removes the twirl from the approaching stream and restricts the assortment in both mean and fluctuating pace. The essential design parameter for honeycomb is the proportion of length to cell hydraulic diameter (L/D) and porosity (stream zone upon full scale area). Recommended L/D extent for honeycomb is 6 to 8 with porosity about 0.8 . Screens are set in the settling chamber for the lessening of disturbance dimension of moving toward stream, this parts up the colossal scale violent whirlpools into different little scale swirls. To viable in lessening choppiness screen must have porosity in the range $0.58-0.89$

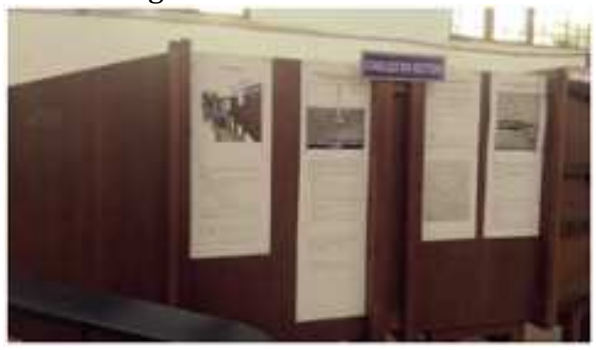

Fig 2.1 Settling Chamber 


\subsection{CONTRACTION CONE}

The contraction quickens the stream to the test section, further diminishing any varieties in speed. The contraction begins with the determination of contraction ratio. For smaller tunnel the compression proportion should be amidst 6 to 9 . A withdrawal design satisfying all criteria will be to such an extent that the division is just stayed away from and the exit non-consistency is identical to or less the greatest decent dimension for the ideal application in most constrained possible length.

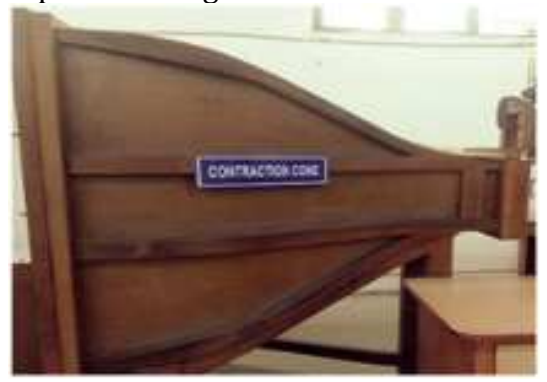

Fig 2.2 Contraction Cone

\subsection{TEST SECTION}

The wind tunnel configuration begins with choosing the test area watching out for the availability and establishment of the test model and instrumentation. The test chamber length must be in the extent of 0.5-3 times its hydraulic diameter. The test chamber is being proposed to test the scaled model of airfoil area. The pressure loss coefficient continues expanding with increment in the test area. So the length of test territory should be as little as could reasonably be expected. The length of the test chamber was set to $1.25 \mathrm{~m}$ for instance 2.215 times the hydraulic diameter of the test segment.

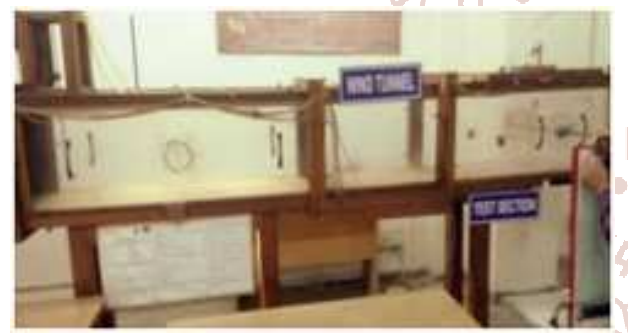

Fig 2.3 Test Section

\subsection{DIFFUSER}

The diffuser is dominatingly used to diminish the speed of stream in the most limited conceivable separation to decrease the heap on drive framework. The move through the diffuser depends upon its geometry portrayed by zone proportion (extent of outlet area to the inlet region) and

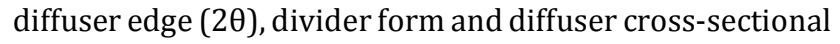
shapes. The present tunnel the previously mentioned proportion is $1.9: 1$, which was managed by the crosssectional zone of the test area, the size of the fan. The resultant included edge is $5.5^{\circ}$ in either the vertical or horizontal plane.

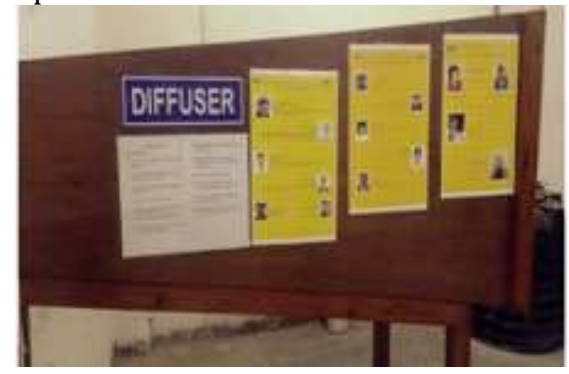

Fig 2.4 Diffuser

\section{$2.5 \quad$ FAN}

The drive framework repays the misfortune in the circuit and chooses the development of the fluid through the test segment. For an air tunnel, two fundamental drive frameworks are a blower and fan. For our circumstance, an axial fan will be used as these are high proficient and produce air current with less choppiness. The power required to keep up reliable consistent course through the wind tunnel is proportionate to the complete misfortune occurring in the move through the passage. These misfortunes are a result of the motor vitality being scattered by vorticity and unsettling influence.

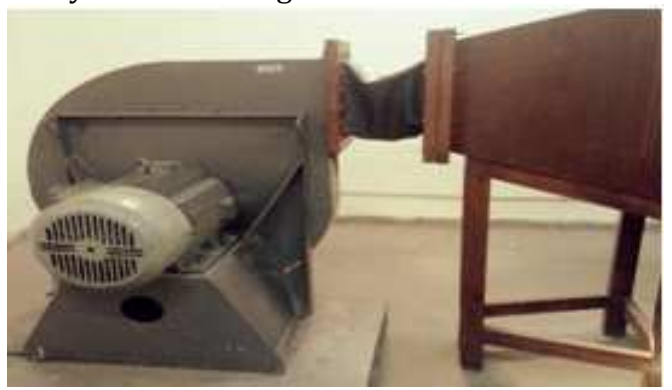

Fig 2.5 Fan

\section{APPARATUS AND INSTRUMENTAION}

The analysis was led in the fluid mechanics research facility in which subsonic wind tunnel is located. This is a low speed open type wind tunnel. Airfoil used is mounted in the center of test section. It has complete 21 in harmony, expanded the full width of the passage. A handle outside of the wind tunnel and appended to the airfoil was utilized to change the approach. This was resolved utilizing a protractor additionally mounted outwardly of the test area. For measuring free stream velocity a pitot tube is used. A multi meter manometer is used to note pressure at various pressure taps on airfoil.

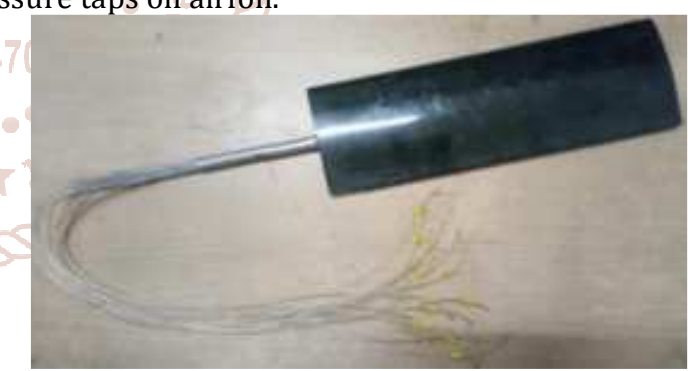

Fig3. Airfoil Section (Testing model)

\section{EXPERIMENTAL PROCEDURE AND CALCULATION}

Firstly, free stream velocity is calculated by measuring static pressure and stagnation pressure (total pressure)

$P t=P s+\left(\rho V^{2} / 2\right)$

$U=\sqrt{ }[2(p t-p s) / \rho]$

The airfoil was set at a 0 degree approach and the wind tunnel worked at around required speed. The pressure at each pressure taps on the airfoil is noted which are further used to calculate coefficient of pressure. By knowing free stream velocity Reynolds Number could be calculated, $\mathrm{Re}=\mathrm{U}^{*} \mathrm{c} / v$ where $\mathrm{u}$ is free stream velocity, $\mathrm{c}$ is chord length and $v$ is kinematic viscosity.

As free stream velocity has been found, Mach number could be achieved

$M=$ free stream velocity/speed of sound 


\subsection{MEASUREMENT OF LIFT AND DRAG}

Drag force is the force that opposes the development of a strong article through a fluid. The drag force is made up of frictional force and pressure force components acting along the direction of flow, coordinated everywhere throughout the outside of the body. The drag force is particularly subject to the state of the body that outcomes in confused formulae for drag force. Hence, the drag equation is utilizing the drag coefficient approach. In this methodology the drag force is related to the stagnation pressure $1 / 2 \rho \mathrm{U}^{2} / 2$ and uncovered territory A. The uncovered territory is taken as anticipated zone parallel to fluid stream for comfort. The relationship is communicated as

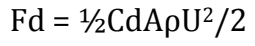

where $\mathrm{Cd}$ is coefficient of drag, $\rho$ is density of fluid, A is projected area.

If the body is symmetric about the direction of flow or vice versa or it is like straight vertical or horizontal flat plate, only drag force act on the body. If the plate is having some angle of attack, a vertical component of resultant force acts which is called lift force, which is calculated as

where $\mathrm{Cl}$ is coefficient of lift.

$$
\mathrm{Fl}=1 / 2 \mathrm{ClA}^{2} \mathrm{U}^{2} / 2
$$

\subsection{CALCULATION OF COEFFICIENT OF PRESSURE}

It defines relative pressure in fluid flow. It is defined
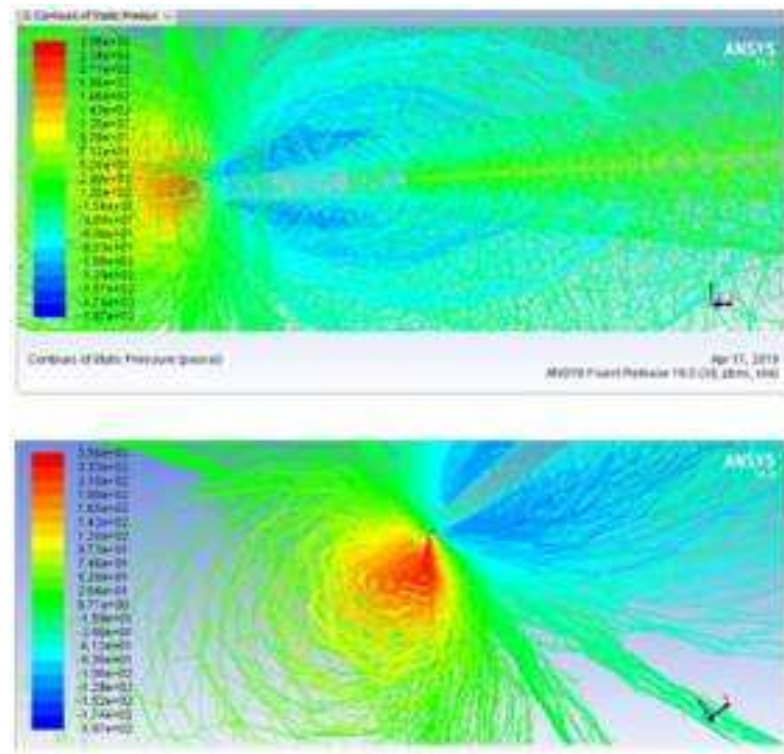

Fig5.1- Pressure distribution at 0 degree approach.

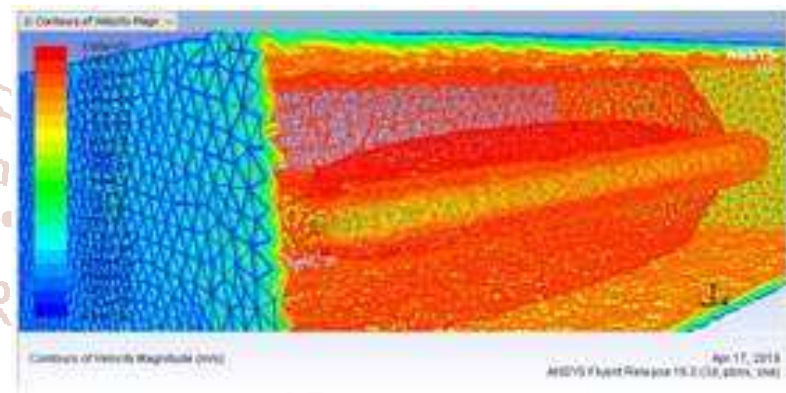

Fig 5.2- Velocity distribution at 0 degree approach. $\mathrm{Cp}=2(\mathrm{P} 2-\mathrm{P} 1) / \rho \mathrm{U}^{2}$

where $\mathrm{P} 2$ is atmospheric pressure and $\mathrm{P} 1$ is pressure at each pressure tap.

0.5

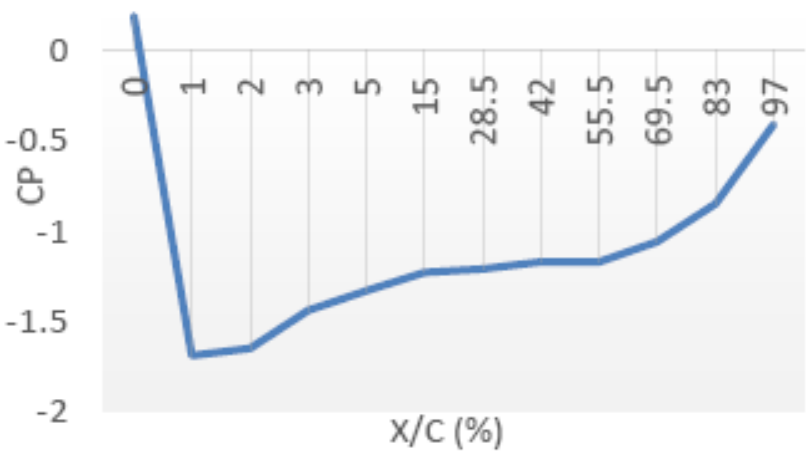

Graph 4.2.1-Relation between $\mathrm{Cp} v / \mathrm{s}$ distance from leading edge

\subsection{DISTRIBUTION OF COEFFICIENT OF PRESSURE}

The weight coefficient of the airfoil's upper surface was negative and the lower surface was certain, along these lines lift drive on airfoil is upward way. We can in like manner see that coefficient of weight distinction is significantly greater on the front edge, while on the back edge it is much lower, consequently showing that the lift power of the airfoil of the airfoil is generally made from the front edge.

\section{VALIDATION OF RESULTS AND DISCUSSIONS}

The analysis is done for 0 degree approach. The static pressure plot and velocity plot are used for analysis.

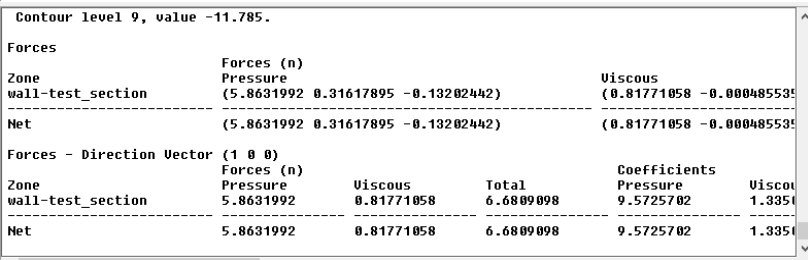

Fig 5.3-Calculation of drag

Drag comes out to be $\mathbf{5 . 8 6 3} \mathbf{N}$

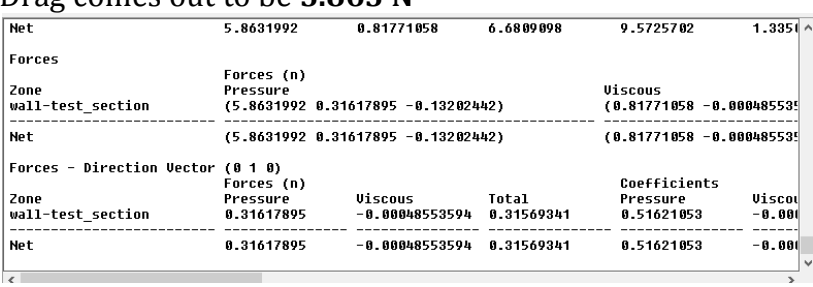

Fig 5.4-Calculation of lift

Lift comes out to be $\mathbf{0 . 3 1 6} \mathrm{N}$

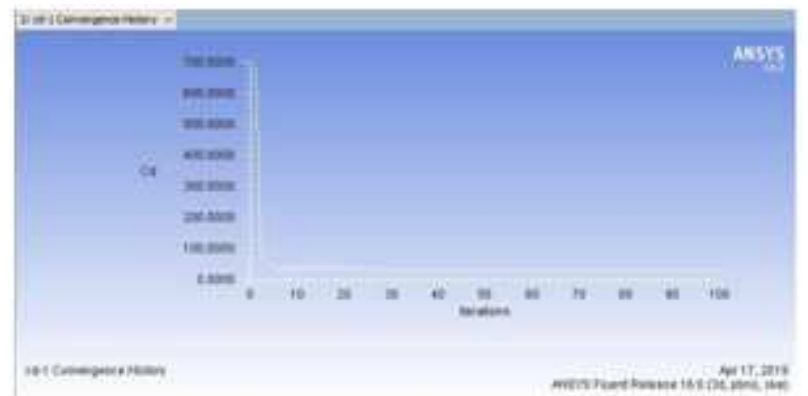

Fig 5.5-Graph depicting values of Coefficient of Drag 
International Journal of Trend in Scientific Research and Development (IJTSRD) @ www.ijtsrd.com eISSN: 2456-6470

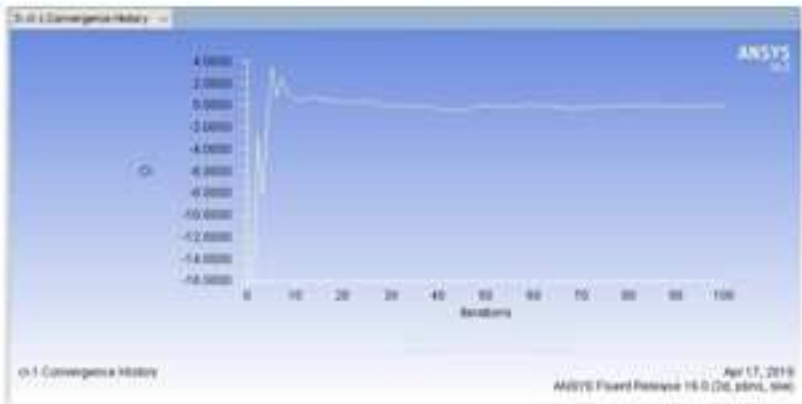

Fig 5.6-Graph depicting values of Coefficient of Lift

\section{CONCLUSIONS AND FUTURE SCOPE}

With the assistance of CFD software ANSYS-Fluent, effective examination of streamlined execution of airfoil area has been conveyed at 0 degree approach utilizing k-epsilon viscous model. The pressure coefficient on upper surface was negative and positive on lower surface, in this way lift on airfoil is upward way. The coefficient of pressure difference is a lot bigger on the front edge while on the trailing edge it was much lower.. The graph of coefficient of lift obtained signifies that lift first increases on leading edge and then becomes constant moving towards trailing edge. As angle of attack is taken 0 degree value of lift obtained is very low.

Experimental values differ from validation values due to difference in geometry and dimension of enclosure i.e. test section.

This test could be performed later on different geometries like spherical body, cylindrical body, buildings, automobiles, etc under different stream velocity.

\section{REFERENCES}

[1] Patel, Karna S., et al. "CFD Analysis of an aerofoil." International Journal of Engineering Research 3.3(2014):154-158.

[2] Kevadiya MayurKumar. "CFD Analysis of Pressure Coefficient for NACA 4412."International Journal of Engineering Trends and Technology, Chennai 4.5 (2013):2041-2043.

[3] Bhushan S. Patil, Hitesh R. Thakare, Computational Fluid Dynamics Analysis of Wind Turbine Blade at Various Angles of Attack and different Reynolds Number, Procedia Engineering, 127(2015), 1363-1369 M. Wegmuller, J. P. von der weid, P. Oberson, and N. Gisin, "High resolution fiber distributed measurements with coherent OFDR," in Proc. ECOC'00, 2000, paper 11.3.2, p.109.

[4] Novel Kumar Sahu, Mr. Shadab Imam, Analysis of subsonic flow over an airfoil NACA 0012 using CFD, International Journal of Innovative Science, Engineering \& Technology, Vol. 2 Issue 4, April 2015 J. Padhye, V. Firoiu and D. Towsley, "Astochastic model of TCP Renocongestion avoidance and control," Univ. of Massachusetts, Amherst, MA, CMPSCI tech. Rep. 99-02, 1999.

[5] Mohamed A. Fouad Kandil, Abdelrady Okasha Elnady, "CFD Analysis of GOE 387Airfoil", IOSR Journal of Mechanical and Civil Engineering(IOSR-JMCE), Volume 14-Issues 5, Sep. - Oct. 2017, PP 80-85.

[6] Fluent 2013 Theory Guide.

[7] Abott, I. H. and von Doenhoff, A. E., "Theory of Wing Sections, "Dover Publications, New York, 1959.

[8] Fox, R. W., \& McDonald, A. T. (1973). Introduction to Fluid Mechanics. John Wiley \& Sons, Inc. 